\title{
Role of certain tree species in absorption of air pollutants caused by heavy metals - Copper, Zinc and Uranium in Tehran
}

\author{
Mehdizadeh Mojdehi Aida' and Ronassi Ali Arash ${ }^{2}$ \\ ${ }^{1}$ Ph.D. student Belarusian National Technical University, Minsk, Belarus \\ ${ }^{2}$ Assistant Professor, Department of Physics, Payame Noor University, Tehran, Iran
}

\begin{abstract}
As environmental pollution to heavy metals is being increased every year, occurrence of serious risks to health of human, animals and plants can be expected. Heavy metals with all of their destructive effects are the main pollutants in the air of big cities. Hence, this study has been conducted with the objective of analysis of role of tree species in absorption of air pollution caused by copper $(\mathrm{Cu})$, zinc $(\mathrm{Zn})$ and $(\mathrm{U})$ uranium in Tehran. According to the climate of studied stations, especially wind velocity and direction, the sampling operation was taken at the end of March and December. The number of samples was also determined based on number of tree species studied (Pinus eldarica, Cupressus arizonica,Platanus orientails), organs of tree species (leaves), number of stations (Mehrabad Airport, Damavand and Chitgar Park) and sampling time scopes (March and December). Sampling was done in frame of statistical plan of completely random block in 3 iterations and the data analysis was done using analysis of variance and using SAS software. The results obtained from this study show that the absorption of cooper, zinc and uranium metals in the leaves of studied trees in polluted stations is more than control station. According to obtained results, uranium concentration in the leaves of studied species increased respectively in Pinus eldarica Medw, Cupressus arizonica Greene and Platanus orientails. The leaves of Pinus eldarica Medwin Mehrabad Airport station have shown highest absorption of this metal. Moreover, obtained results show that the cooper absorbed by leaves of studied species is increased respectively in Pinus eldarica Medw, Cupressus arizonica Greene and Platanus orientails. In terms of the effect of station on absorption of cooper, the species in the Mehrabad station have shown high absorption of this metal. The concentration of absorbed zinc in leaves of studied species is also increased respectively in Pinus eldarica Medw, Cupressus arizonica Greene and Platanus orientails and the zinc absorbed by species of Mehrabad station has shown the highest level. It is concluded that the absorption level of $\mathrm{Cu}, \mathrm{Zn}$ and $\mathrm{U}$ in leaves of studied trees in polluted stations has been higher than control stations and Pinus eldarica Medw can be used as an index of absorption of heavy metals such as $\mathrm{Cu}, \mathrm{Zn}$ and $\mathrm{U}$.
\end{abstract}

KEY WORDS: TREE SPECIES, HEAVY METALS, COPPER, ZINC, URANIUM

ARTICLE INFORMATION:

*Corresponding Author:

Received $18^{\text {th }}$ Oct, 2017

Accepted after revision $12^{\text {th }}$ Dec, 2017

BBRC Print ISSN: 0974-6455

Online ISSN: 2321-4007 CODEN: USA BBRCBA

Thomson Reuters ISI ESC and Crossref Indexed Journal

NAAS Journal Score 2017: 4.31 Cosmos IF: 4.006

๑ A Society of Science and Nature Publication, 2017. All rights reserved.

Online Contents Available at: http//www.bbrc.in/

DOI: $10.21786 / \mathrm{bbrc} / 10.4 / 23$ 


\section{INTRODUCTION}

As environmental pollution to heavy metals is being increased every year and can ultimately lead to serious risks to health of human, animals and plants, heavy metals with all of their destructive effects can be the main pollutants in the air of big cities. Therefore, one of the most fundamental issues gaining attention of scientists to heavy metals is lack of metabolism of these metals in the body. According to increasing population and the industrialization phenomenon of societies, more and more use of fossil fuels, especially oil products to produce electricity, transport systems and industrial and house uses, has led to occurrence of environmental problems because of production of hydrocarbons, polluted gases and heavy metals (Naderi et al, 2012, Zhou et al., 2017, Suvarapu and Baek, 2017).

As a result of rapid industrial growth over the decades, soil pollution to heavy metals has been increased. Although heavy metals can be existed in soil naturally, high percentages of these metals could be the outcome of human activities such as use of chemicals,organic modifiers, animal fertilizers, mineral processing, sewage sludge and waste from the iron and steel industry, mines, road transport and so on .Vehicles can be one of the main sources of producing heavy metals at the cities, which can cause pollution of soil around the roads by production of pollutants and making them enter to the environment and into the air. According to various studies conducted in field of heavy elements, the metals such as cooper $(\mathrm{Cu})$, lead $(\mathrm{Pb})$ and zinc $(\mathrm{Zn})$ have shown high importance because of long half lifetime in body of human and other animals and because of being toxic (Suvarapu and Baek, 2017, Qiutong \& Mingkui, 2017 and Sistani et al, 2017, Xu et al., 2017).

In field of role of tree species in adsorption of air pollution caused by heavy metals, various studies have been conducted. Cheraghi et al (2012) have conducted a study under the title of "analysis of heavy metals in bed, leaves and stem of Avicennia marina in Khuzestan" and have determined concentration of heavy metals such as $\mathrm{Cu}, \mathrm{Pb}, \mathrm{Ni}$ and $\mathrm{Cd}$ in sediments of Imam Khomeini Port Zone and Avicennia Marina and analysis of mobility of these metals based on enrichment percentage. 9 stations were selected in theMangrove stations and some samples of leaves and stem of Mangrove were collected, along with sediments of the zone. The results showed that concentration of metals in step of plants was more than leaves. Moreover, there was significant correlation between concentration of metals in stem and sediments (Cheraghi et al, 2012).

Maddah et al (2013) measured the amount of sediment in extracts resulted from stem, shoot and leaves and soil of flowerpots at the end of Nov using ICP device. The results showed that P.Sylvetris specie is the suitable specie forphytoremediation of lead. In the concentration of $800 \mathrm{ppm}$, the contamination of $\mathrm{Pb}$ in stem and shoots is more than leaves; although in concentration of $1600 \mathrm{ppm}$, the highest accumulation of lead is in stem and leaves. Comparing different horizons of soil showed that $\mathrm{Pb}$ has been mainly contaminated in surface horizon (Maddah et al, 2013).

Kardar et al (2015) has studied cadmium adsorption in organs of Fraxinus excelsior and Cupressus arizonica in Isfahan. To this end, some samples of leaves and surface steps of trees were prepared linearly and randomly in 3 iterations in late spring and summer and the cadmium concentration in them was measured using atom adsorption device. The results show that cadmium absorption level in areal organs of Cupressus arizonica happens more than Fraxinus excelsior and cadmium absorption in leaves of studied species is more than stem. Moreover, cadmium absorption in different organs of species in polluted station was more than other stations and the highest level of cadmium absorption was observed in September and the lowest level was observed in June (Kardar et al, 2015).

Kord et al (2011) has conducted a study under the title of refinement of soil polluted to $\mathrm{Zn}$ by means of tree species of Pinus Eldarica Medw, Cupressus arizonica Greene, Robinia peseudoacacia,Fraxinus rotundifolia Mill andUlmus carpinifolia var umbraculifera Rehd in Tehran. For this purpose, in summer in polluted stations (Azadi, Bahman and Bazar) and control station (Aghdasieh), a transect was selected due to wind direction and sampling was done in 3 iterations from leaves and surface stems of trees in frame of absolutely random statistical plan and the $\mathrm{Pb}$ concentration in each sample was measured using atom absorption device model Varian220. The results showed that Pinus eldarica Medw, Cupressus arizonica Greene and Robinia peseudoacacia species have shown respectively highest $\mathrm{Pb}$ concentration in aerial organs (14.39ppm, 11.91ppm and 9.72ppm) and highest coefficient of Pbtransfer from the underground to the limb (respectively 3.49, 2.99 and 2.82). Accordingly and due to adequate coping conditions, the 3 species have been used to refine $\mathrm{Pb}$-contaminated soil in similar zones (Kord et al, 2011).

Afshari et al studied heavy metal pollution using pollution factor in soil of lands with various uses in central zone of Zanjan Province. To evaluate 241 samples of surface soil based on systematic approach, nesting was done in depth of 0-10c of agricultural, farming and urban uses. The results showed that 1time more of the pollutant is in field soil and 0.4, 5.0 and 2.0 and 1 of total $\mathrm{Pb}, \mathrm{Zn}, \mathrm{Cd}$ and $\mathrm{Cu}$ in samples soils and respectively the overall concentration of $\mathrm{Fe}, \mathrm{Mg}$, $\mathrm{Co}$ and $\mathrm{Ni}$ is lower than field concentration of these metals. High amounts 
of pollution factor of $\mathrm{Pb}, \mathrm{Zn}, \mathrm{Cd}$ and $\mathrm{Cu}$ was observed in urban uses and the pollution factor of $\mathrm{Fe}, \mathrm{Mg}, \mathrm{Cr}$, Co and Ni was observed in agricultural and farming uses. Finally, the results showed that the metals in first group are mostly under the effect of human activities and the metals in second group are mostly affected by mother materials in the zone.

Shabanian and Chanor (2013) studied thebiodegradability of wooden species used in urban foresting of Sanandaj. Contamination of some heavy metals such as $\mathrm{Pb}$, $\mathrm{Zn}, \mathrm{Cd}$ and $\mathrm{Mg}$ was measured in leaves ofOriental plain, elm, asparagus, Croissant and black pine in Sanandaj's City Center (as polluted zone) and the area of Kurdistan University (as control zone). The results showed that contamination of $\mathrm{Pb}, \mathrm{Zn}$ and $\mathrm{Cd}$ in leaves of majority of species in polluted zone was significantly higher than control zone at the level of 95\%. In the polluted zone, the highest contamination of $\mathrm{Pb}$ and $\mathrm{Cd}$ was observed inCroissant, most $\mathrm{Zn}$ contamination was observed in asparagus and the most $\mathrm{Mg}$ contamination was observed in elm, (Shabanian and Chanor 2013).

Sistani et al (2017) conducted a cross-sectional and descriptive-analytical research under the title of "heavy metals contamination in adjacent soil of Kerman Steel Industry: evaluation of metal enrichment and degree of pollution". In this study, they found that the most concentration has been belonged to steel and concentration of other metals such as $\mathrm{Pb}, \mathrm{Cd}$ has been significantly under the effect of steel complexes and some plans should be made for the surrounding area to reduce emission of pollutants. Therefore, this study has been conducted to investigate the amount of heavy metal absorption in some tree species in Tehran.

\section{MATERIAL AND METHODS:}

In this study, to measure the amount of heavy metal absorption in some tree species in Tehran, urban areas such as parks, boulevards, streets and highways and industrial districts used various tree species are selected as stations and research station. Then, during certain time intervals, through sampling leaves, stems and shoots of species, the contamination of each organ was determined. Accordingly, species with highest level of heavy metal absorption and with higher resistance against these metals were detected and were used in the zones polluted to these metals.

As the status of pollution caused by studied heavy metals is not same in whole city, sampling operation should be taken in form of an index of pollution status, so that it can consider minimum and maximum and average levels of pollution. To this end and due to reports of air pollution by Environmental Protection Agency and Transport and Traffic Agency of Tehran,
Mehrabad Airport station was selected as station with high air pollution; Damavand Station was selected as station with low pollution. Chitgar station was selected as control station due to low pollution to be the basis for comparison with other polluted stations.

After determining the polluted and control stations, the studied species were identified and selected in each station. The desired species were selected based on majority in Tehran and dominance in all studied area from Evergreen and Easter species andBroad leaf and needle leaf species. The tree species existed in all studied stations in common were detected and board leaf Platanus orientails and needle leaf Pinus Eldarica Medw andCupressus arizonica Greene were selected to take required comparisons to determine heavy metal absorption level among different organs like leaves.

Sampling was done on leaves of trees in such way that leaf samples were carefully separated from petiole location. Moreover, according to position of the leaves on the crown of tree, an arrangement was taken to select leaves from whole crown of tree. Number of samples was also determined due to number of studied tree species (Pinus Eldarica Medw, Cupressus arizonica Greene, Platanus orientails), organs of tree species (leave), number of stations (Mehrabad Airport, Damavand and Chitgar Park) and sampling time scopes (March and December) and iteration of examinations (3 iterations). Hence, according to the climate of studied stations, especially wind speed and direction, sampling was done in late March and late December.

In this study, the effect of various factors such as tree species, research stations, and time intervals of sampling and concentration of heavy metals in leaves of trees was studied. In frame of absolutely random block plan and in 3 iterations, sampling was done and the data analysis was done using analysis of variance and using SAS software. Drawing diagrams and graphs was also done using Excel software.

\section{RESULTS}

The results obtained from analysis of variance of mean square in leaves of tree species for 3 elements of $\mathrm{Cu}, \mathrm{Zn}$ and $U$ in time scope of March and December in 3 studied zones are presented in table 1 .

According to table 1, the results obtained from analysis of variance in March showed that the effect of specie is significant for all studied properties at the probability level of $1 \%$ and the results have been insignificant for $\mathrm{Cu}$ concentration in leaf. Moreover, the results obtained from analysis of variance in December showed that the effect of specie for all studied properties is significant at the probability level of $1 \%$ and the results obtained from 


\begin{tabular}{|c|c|c|c|c|c|c|c|}
\hline \multirow{3}{*}{$\begin{array}{l}\text { Sources of } \\
\text { variations }\end{array}$} & \multirow{3}{*}{$\begin{array}{l}\text { Degrees of } \\
\text { freedom }\end{array}$} & \multicolumn{6}{|c|}{ Mean Square } \\
\hline & & March & December & March & December & March & December \\
\hline & & Leaf $\mathrm{Cu}$ & Leaf $\mathrm{Cu}$ & Leaf Zn & Leaf Zn & Leaf U & Leaf U \\
\hline Specie & 2 & $* * 35.65$ & $* * 1.45$ & $* * 1.23$ & $* * 1.47$ & $* * 0.98$ & ${ }^{* * *} 0.85$ \\
\hline Station & 2 & $* * 43.55$ & ${ }^{* *} 1.64$ & $* * 1.32$ & ${ }^{* *} 10.21$ & $* * 0.21$ & ***032/ \\
\hline SpeciexStation & 3 & $* * 2.36$ & ${ }^{* * *} 0.08$ & $* * 0.12$ & **0.09 & ${ }^{*} 0.12$ & $* * 0.9$ \\
\hline Error & 30 & 0.35 & 0.09 & 0.05 & 0.01 & 0.18 & 0.15 \\
\hline \multicolumn{2}{|c|}{ Coefficient of variation (\%) } & 10.38 & 15.35 & 8.11 & 15.11 & 0.17 & 0.75 \\
\hline
\end{tabular}

uranium concentration in leaf and $\mathrm{Cu}$ contamination in leaf are not significant.

According to figure 1, the results of mean comparisons showed that the mutual effect of station on $\mathrm{Zn}$ concentration in leaves of these trees was significant at the level of $95 \%(\mathrm{p}<0.05)$. On the other hand, the results of multiple comparisons using Duncan test showed that the highest $\mathrm{Zn}$ concentration in Pinus eldarica Medw leaf was at Mehrabad Airport station (1.07ppm) and the lowest concentration was at Chitgar station in Platanus orientails (1.00ppm).

According to figure 2, the results of mean comparisons showed that the mutual effect of station on $\mathrm{Cu}$ concentration in leaves of these trees was significant at the level of 95\% $(p<0.05)$. On the other hand, the results of multiple comparisons using Duncan test showed that the highest $\mathrm{Cu}$ concentration in Pinus eldarica Medw leaf belonged to Mehrabad Airport station being $2.04 \mathrm{ppm}$ and the lowest concentration belonged to Chitgar station inPlatanus orientails which was $1.63 \mathrm{ppm}$.

According to figure 3, the results of mean comparisons showed that the mutual effect of station on $U$ concentration in leaves of these trees was significant at the level of $95 \%(\mathrm{p}<0.05)$. On the other hand, the results of multiple comparisons using Duncan test showed that the highest U concentration in Pinus Eldarica Medw leaf was at Mehrabad Airport station being $0.99 \mathrm{ppm}$ and the lowest concentration at Chitgar station in Platanus orientails was $1.00 \mathrm{ppm}$.

According to figure 4, the results of mean comparisons showed that the mutual effect of station on $\mathrm{Zn}$ concentration in leaves of these trees was significant at the level of 95\% $(p<0.05)$. On the other hand, the results of multiple comparisons using Duncan test showed that the highest $\mathrm{Zn}$ concentration in Pinus Eldarica Medw leaf was at Mehrabad Airport station (3.36 ppm) and

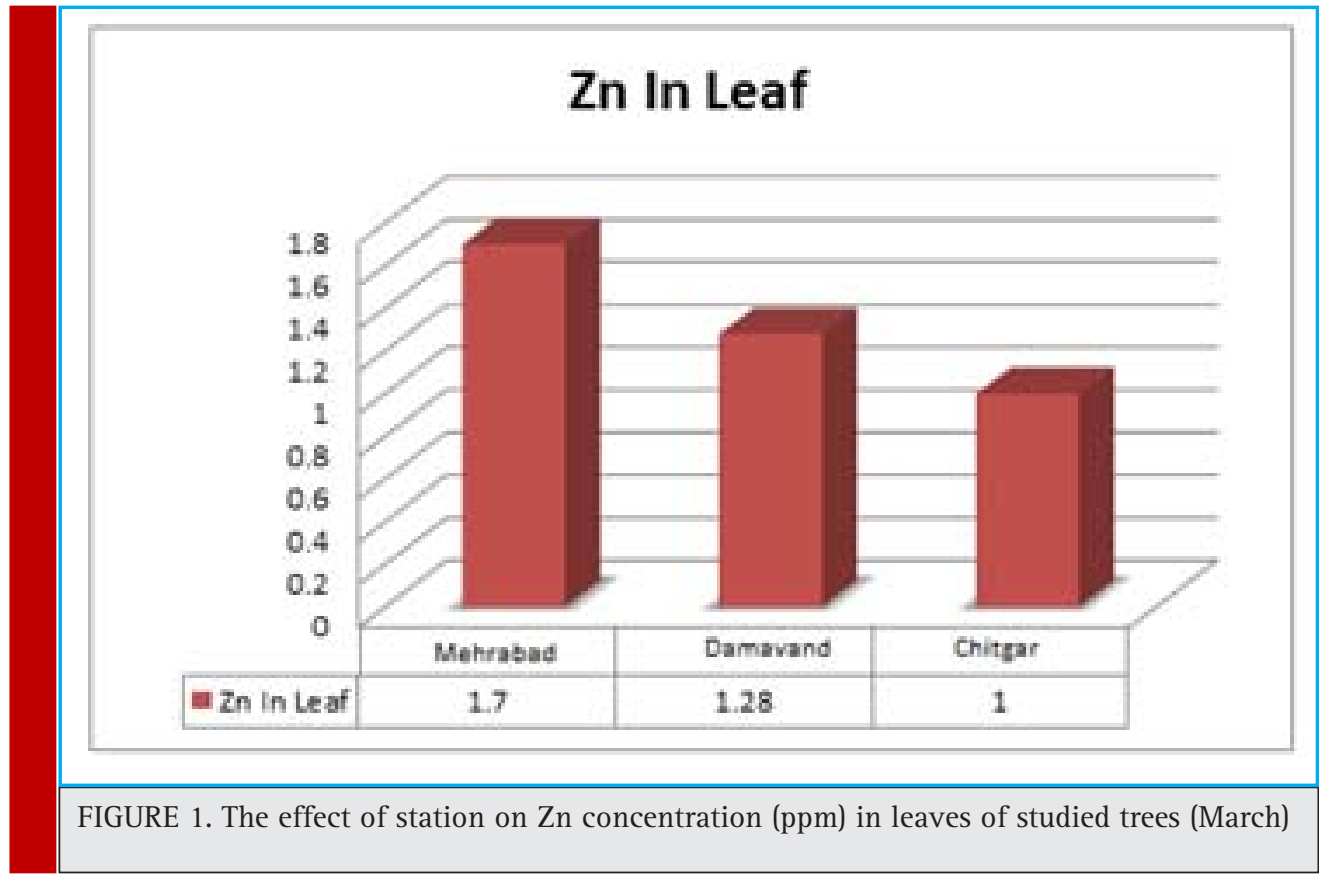




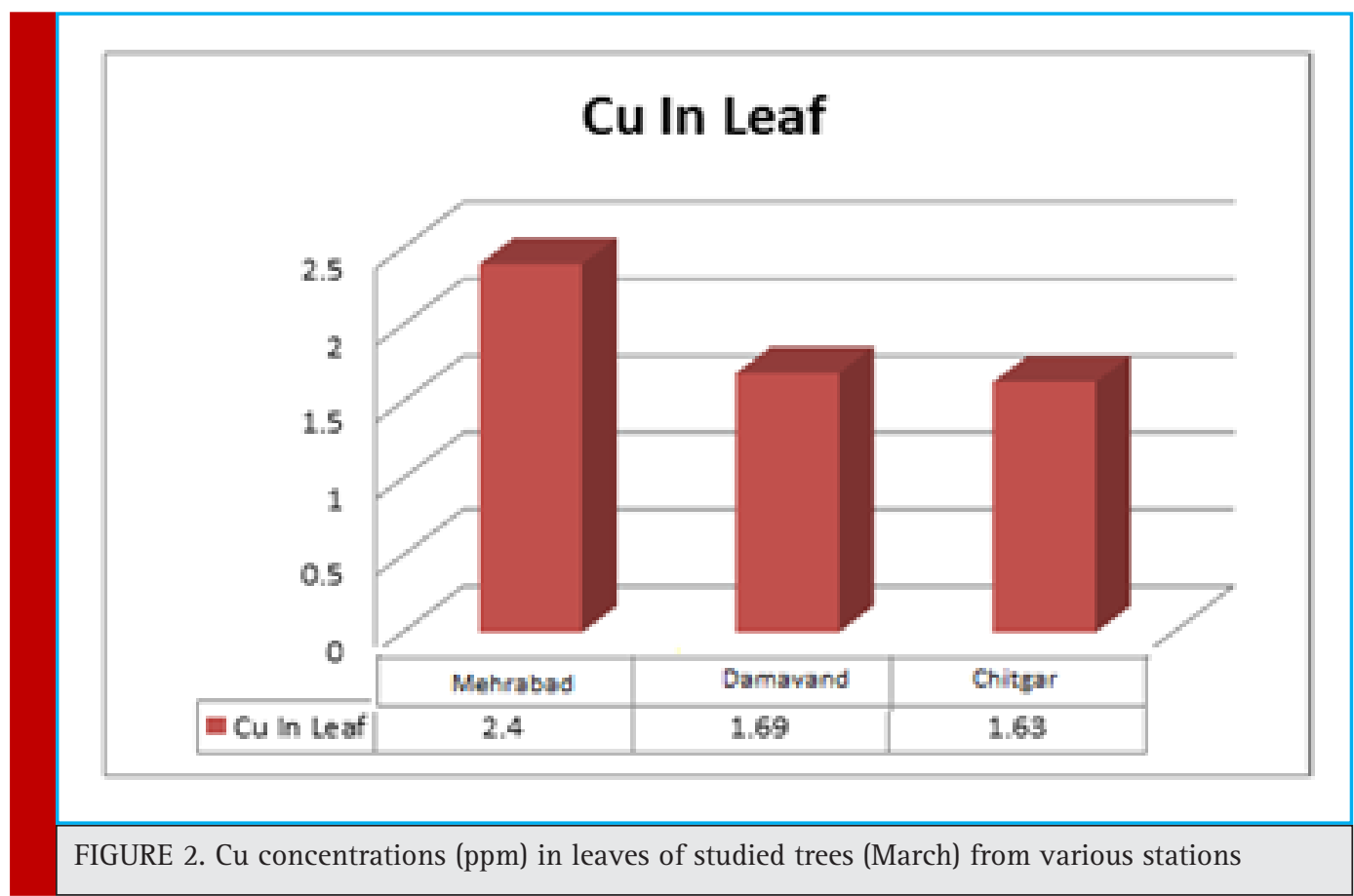

the lowest concentration at Chitgar station in Platanus orientails was $1.18 \mathrm{ppm}$.

According to figure 5, the results of mean comparisons showed that the mutual effect of station on $\mathrm{Cu}$ concentration in leaves of these trees was significant at the level of 95\% $(p<0.05)$. On the other hand, the results of multiple comparisons using Duncan test showed that the highest $\mathrm{Cu}$ concentration in Pinus Eldarica Medw leaf belonged to Mehrabad Airport station being 2.74 ppm and the lowest concentration was at Chitgar station in leaves of Cupressus arizonica Greene being $1.85 \mathrm{ppm}$.

According to figure 6, the results of mean comparisons showed that the mutual effect of station on U concentration in leaves of these trees was significant at the level of $95 \%(p<0.05)$. On the other hand, the results of multiple comparisons using Duncan test showed that the highest

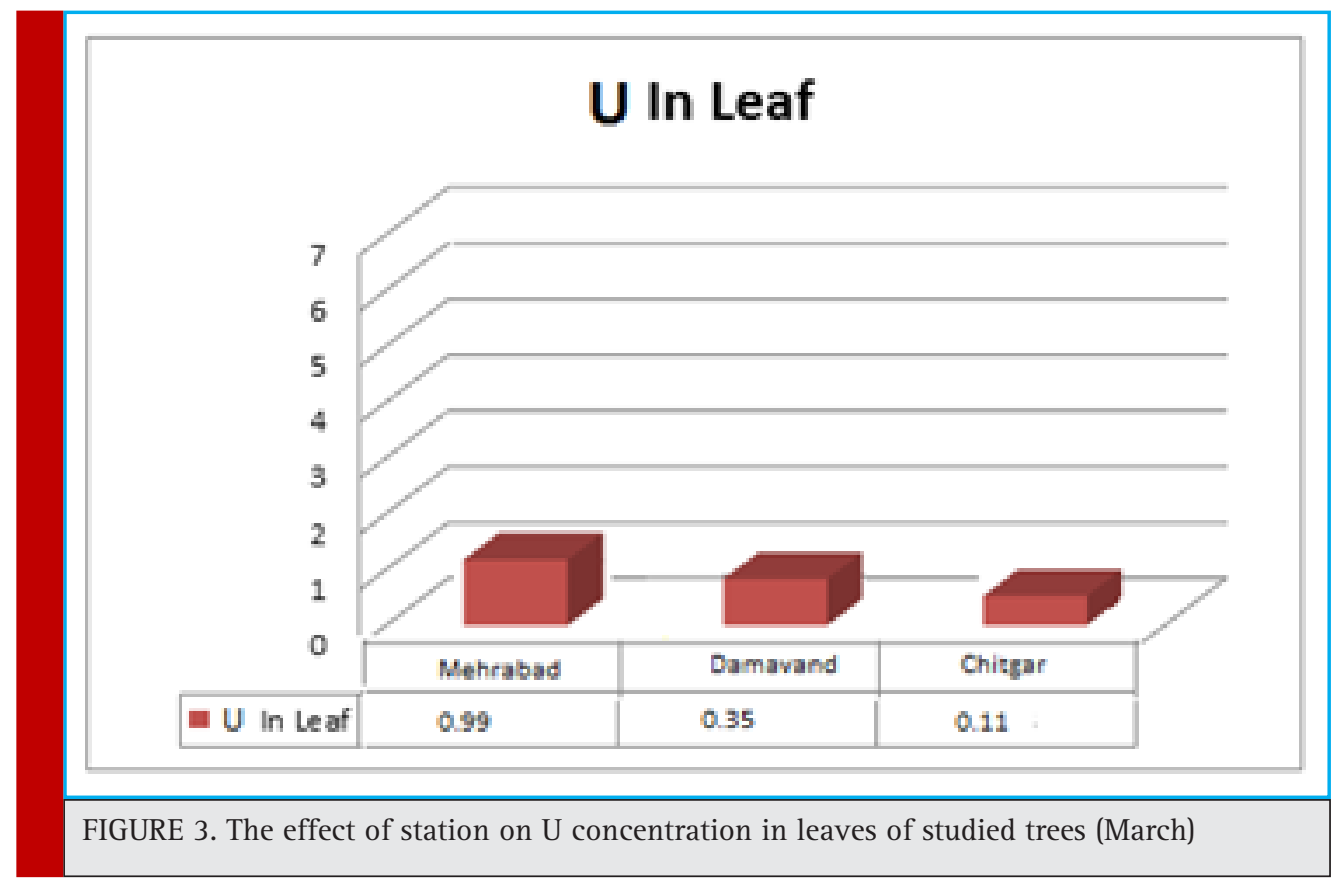

768 ROLE OF CERTAIN TREE SPECIES IN ABSORPTION OF AIR POLLUTANTS

Bioscience Biotechnology Research Communications 


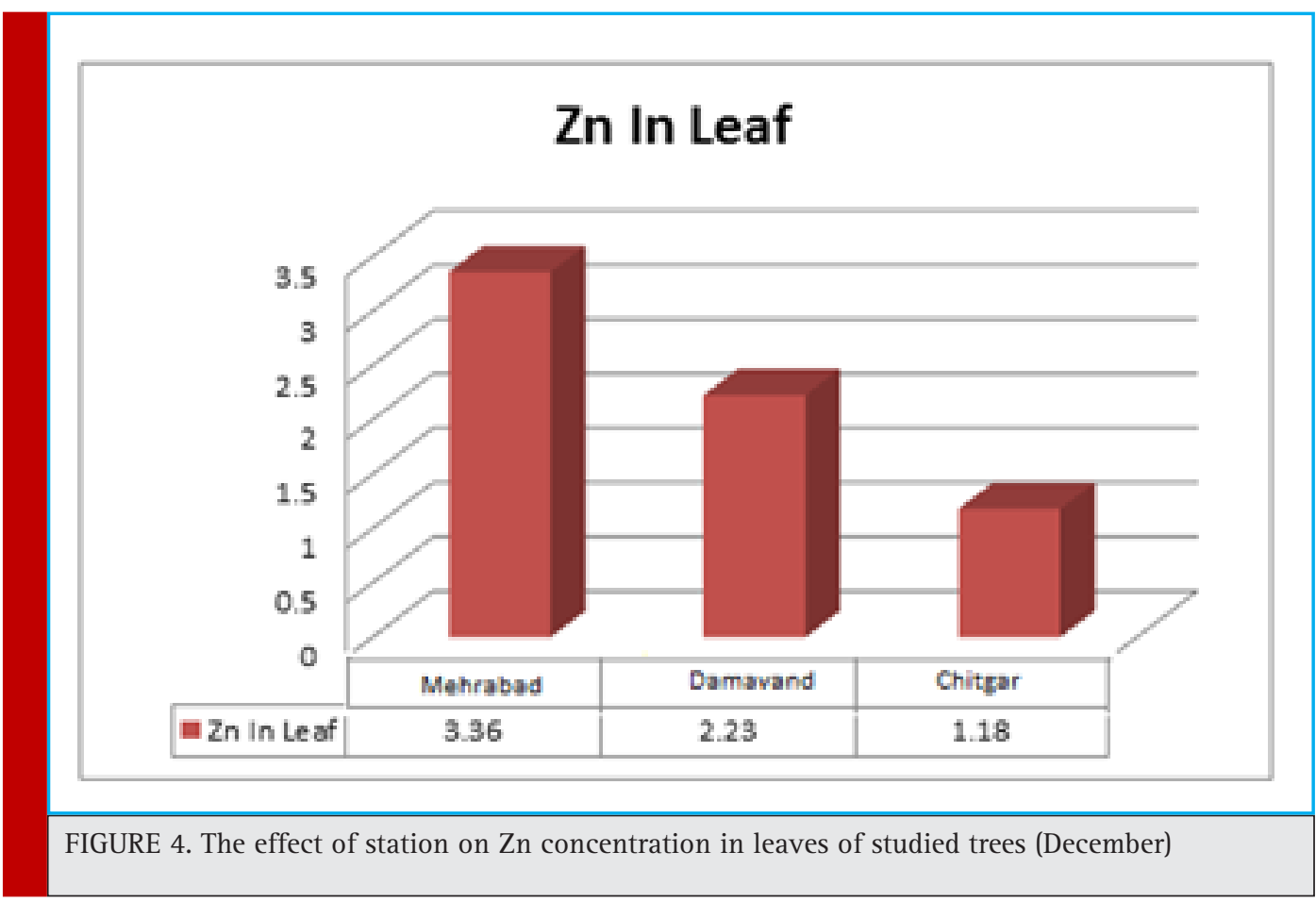

U concentration in Pinus Eldarica Medw leaf belonged to Mehrabad Airport station being $0.99 \mathrm{ppm}$ and the lowest concentration belonged to Chitgar station in leaves of Cupressus arizonica Greene which was $0.22 \mathrm{ppm}$.

According to figure 7, the results of mean comparisons showed that the mutual effect of specie on $\mathrm{Zn}$ concentration in leaves of these trees was significant at the level of $95 \%(\mathrm{p}<0.05)$. On the other hand, the results of multiple comparisons using Duncan test showed that the highest $\mathrm{Zn}$ concentration was in Pinus Eldarica Medw leaf (1.61 ppm) and the lowest concentration was in leaves of nlatanus orientails (1.29 ppm).

According to figure 8 , the results of mean comparisons showed that the mutual effect of species on $\mathrm{Cu}$

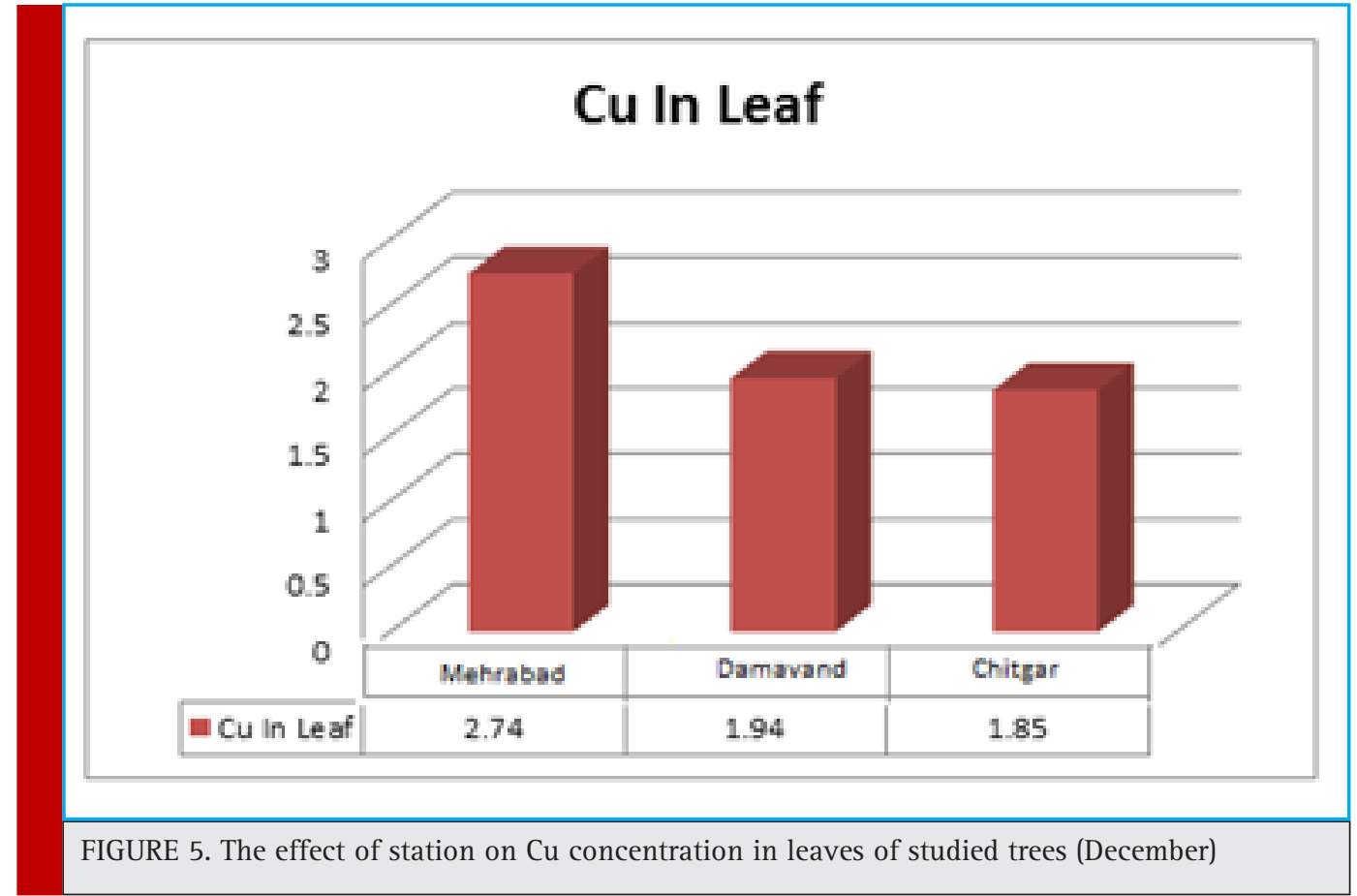




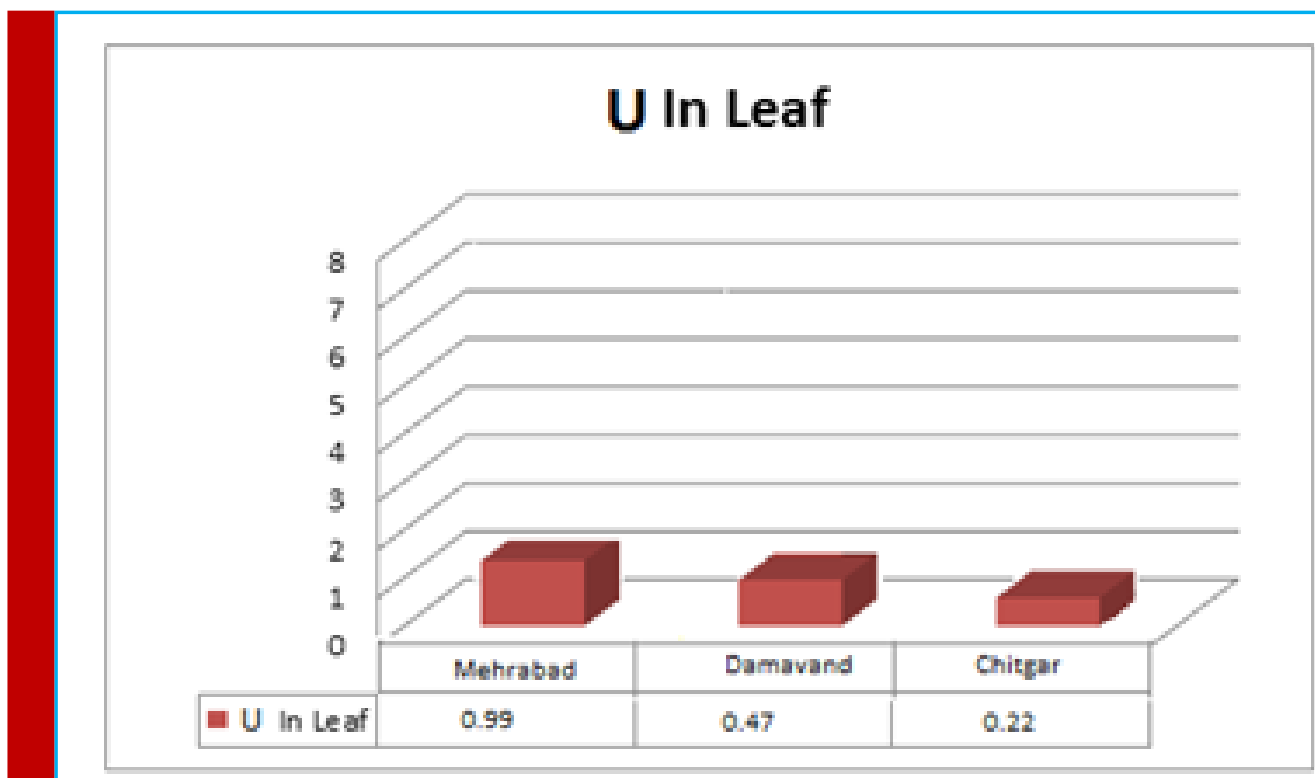

FIGURE 6. The effect of station on U concentration in leaves of studied trees (December)

concentration in leaves of these trees was significant at the level of $95 \%(\mathrm{p}<0.05)$. On the other hand, the results of multiple comparisons using Duncan test showed that the highest $\mathrm{Cu}$ concentration was in the leaves of Pinus eldarica Medw (2.61 ppm) and the lowest concentration belonged to Platanus orientails which was $1.08 \mathrm{ppm}$.

According to figure 3 , the results of mean comparisons showed that the mutual effect of specie on U con- centration in leaves of these trees was significant at the level of $95 \%(\mathrm{p}<0.05)$. On the other hand, the results of multiple comparisons using Duncan test showed that the highest U concentration belonged to Pinus Eldarica Medw leaf to $0.91 \mathrm{ppm}$ and the lowest concentration belonged to Platanus orientails to $0.17 \mathrm{ppm}$.

According to figure 10, the results of mean comparisons showed that the mutual effect of specie on $\mathrm{Zn}$ con-

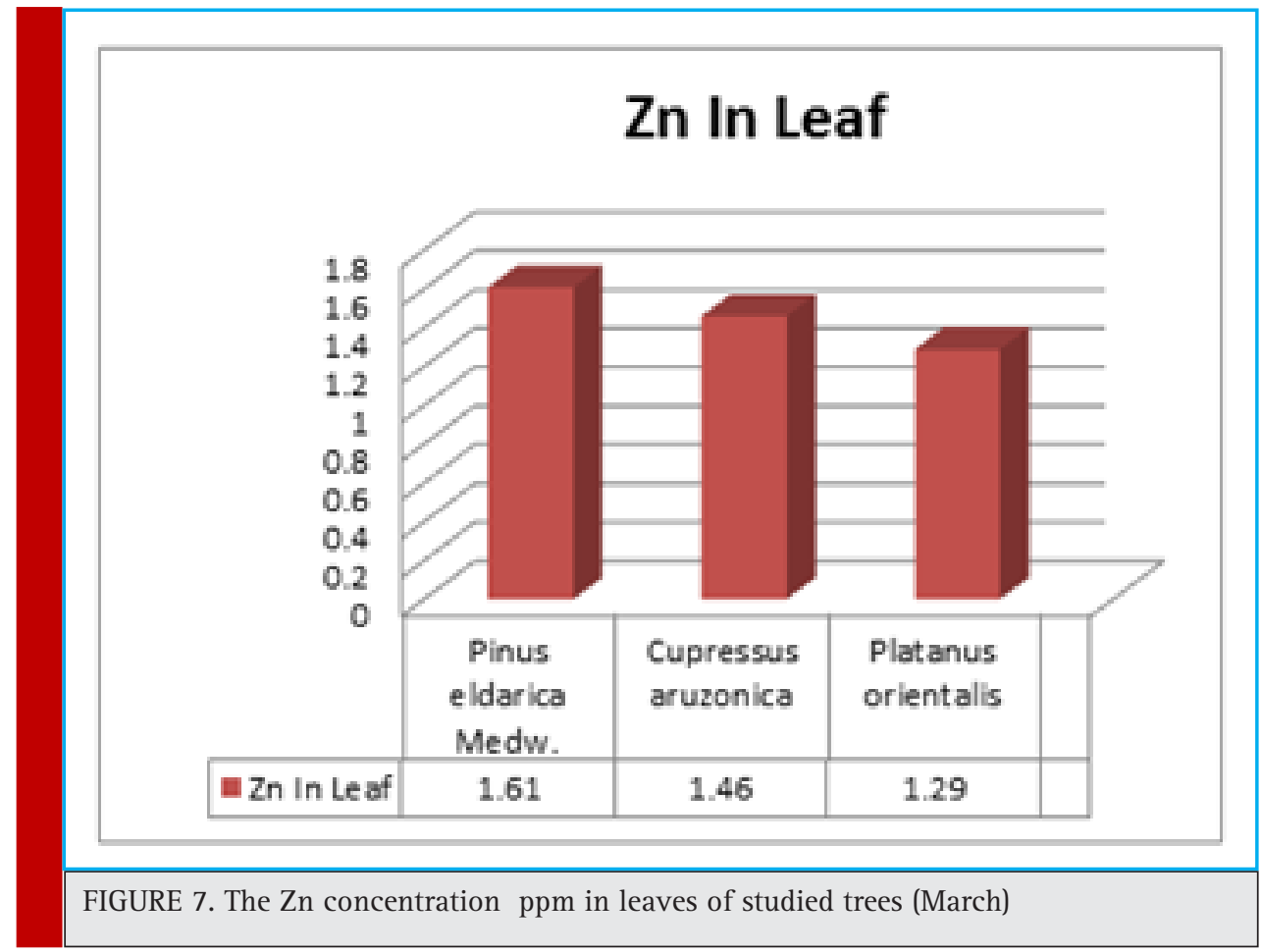




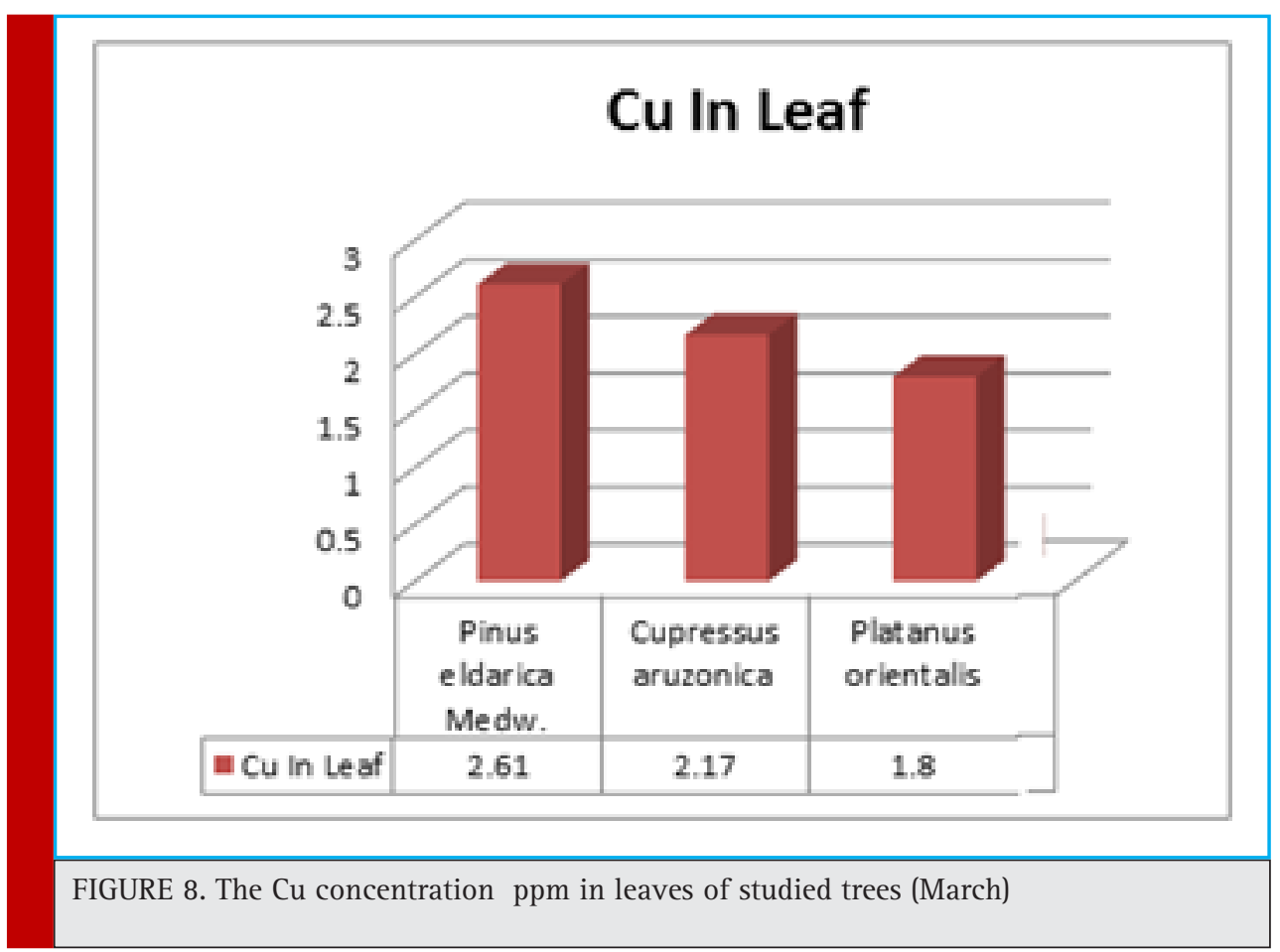

centration in leaves of these trees was significant at the level of $95 \%(p<0.05)$. On the other hand, the results of multiple comparisons using Duncan test showed that the highest $\mathrm{Zn}$ concentration belonged to Pinus eldarica Medw leaf to $2.47 \mathrm{ppm}$ and the lowest concentration was in Cupressus arizonica Greene (2.05 ppm).
According to figure 11, the results of mean comparisons showed that the mutual effect of specie on $\mathrm{Cu}$ concentration in leaves of these trees was significant at the level of $95 \%(p<0.05)$. On the other hand, the results of multiple comparisons using Duncan test showed that the highest $\mathrm{Cu}$ concentration was in Pinus eldarica Medw

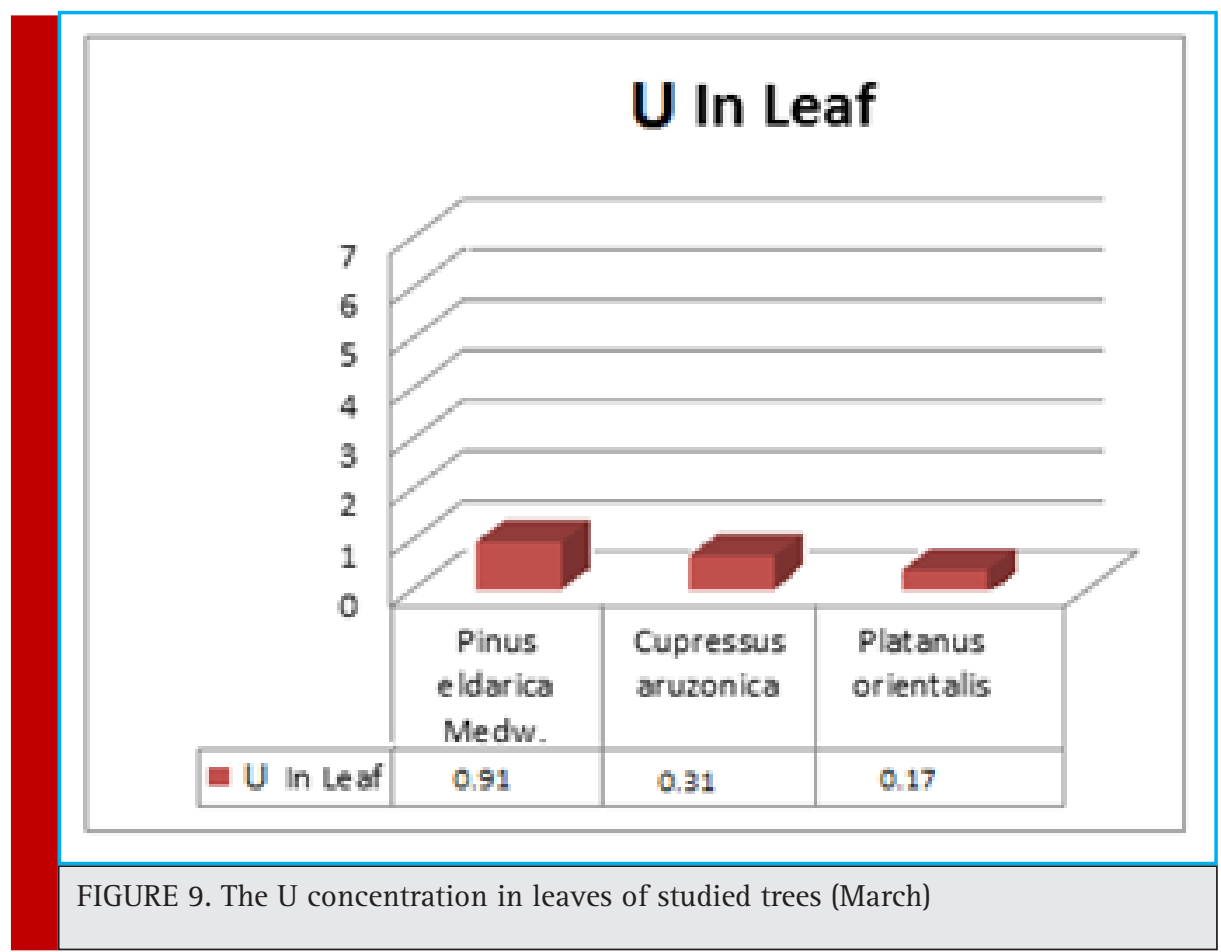




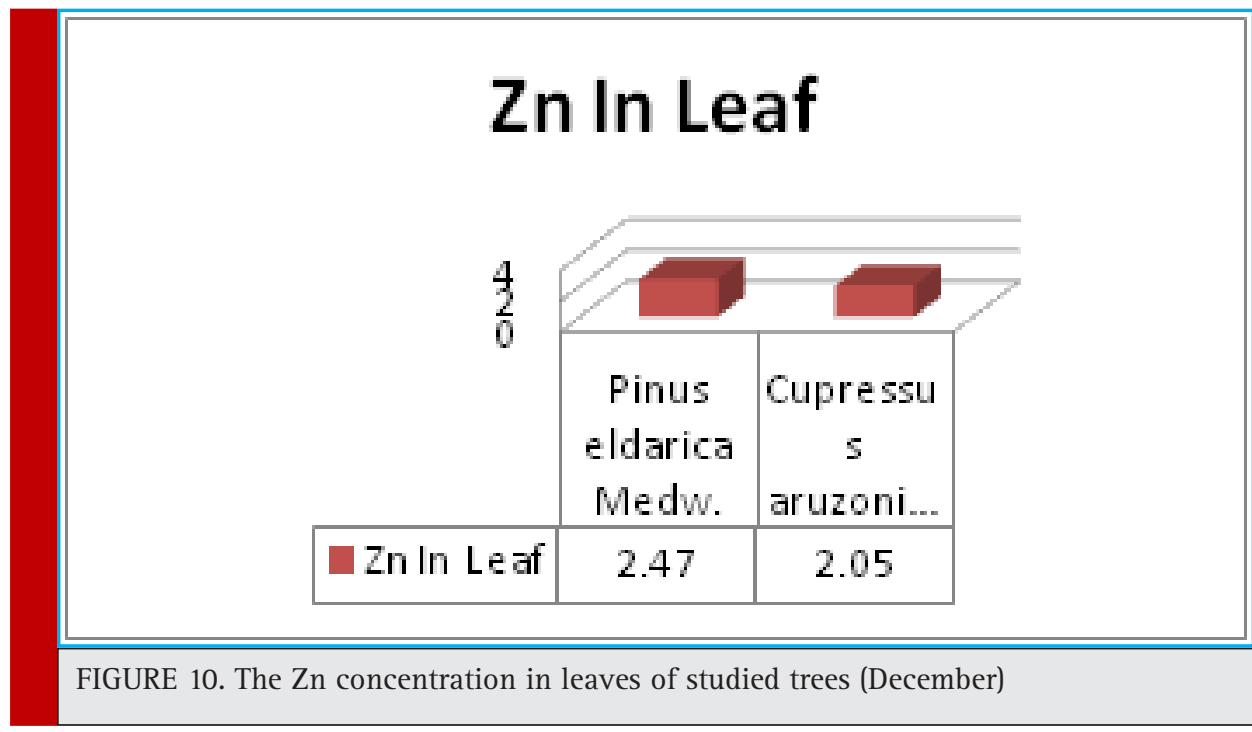

(2.38 ppm) and the lowest concentration was in Cupressus arizonica Greene being 1.97 ppm.

According to figure 12, the results of mean comparisons showed that the mutual effect of specie on U concentration in leaves of these trees was significant at the level of $95 \%(p<0.05)$. On the other hand, the results of multiple comparisons using Duncan test showed that the highest Uranium concentration was in Pinus eldaricaleaves which was $0.27 \mathrm{ppm}$ and the lowest concentration of $0.11 \mathrm{ppm}$ was in the leaves of Cupressus arizonica.

\section{DISCUSSION AND CONCLUSION}

This study has been conducted with the aim of analysis of the role of three tree species in absorbing the air pollution caused by $\mathrm{Cu}, \mathrm{Zn}$ and Uranium in Tehran.
This study has been conducted in 3 stations including Mehrabad Airport, Damavand and Chitgar stations. In this study, it was found that absorption of heavy metals ( $\mathrm{Cu}, \mathrm{Zn}$ and Uranium) in leaves of studied trees in polluted stations was more than control station and it is increased respectively in Chitgar, Damavand and Mehrabad stations. As the environment plays key role in absorption of metals by plant species, it seems that Mehrabad Airport has shown higher level of absorption of the metal in leaves of tree species than other stations due to high concentration of metals in the air. Heydari et al (2005) have claimed that $\mathrm{Pb}$ absorption by plants can be increased due to concentration of this metal in the environment. Marry et al (1996) have also mentioned in their investigations that $\mathrm{Pb}$ absorption level by plants is in significant correlation with concentration of this metal in the environment.

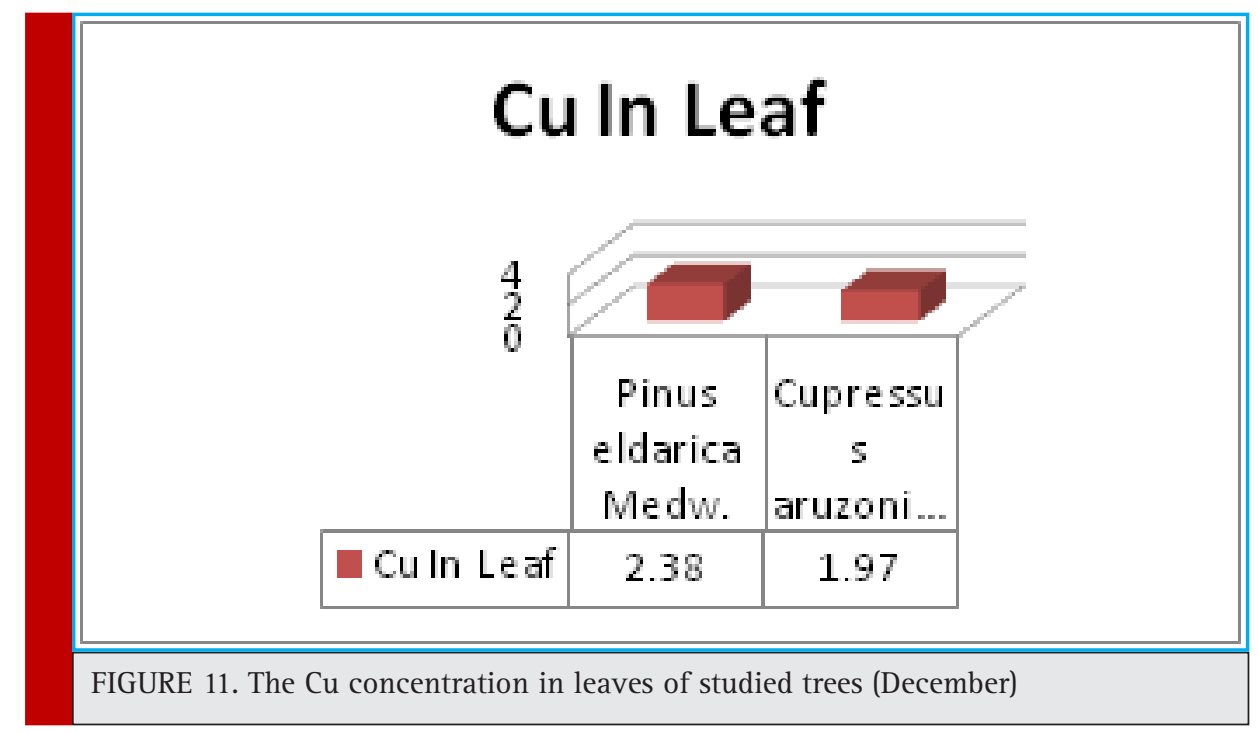

772 ROLE OF CERTAIN TREE SPECIES IN ABSORPTION OF AIR POLLUTANTS 


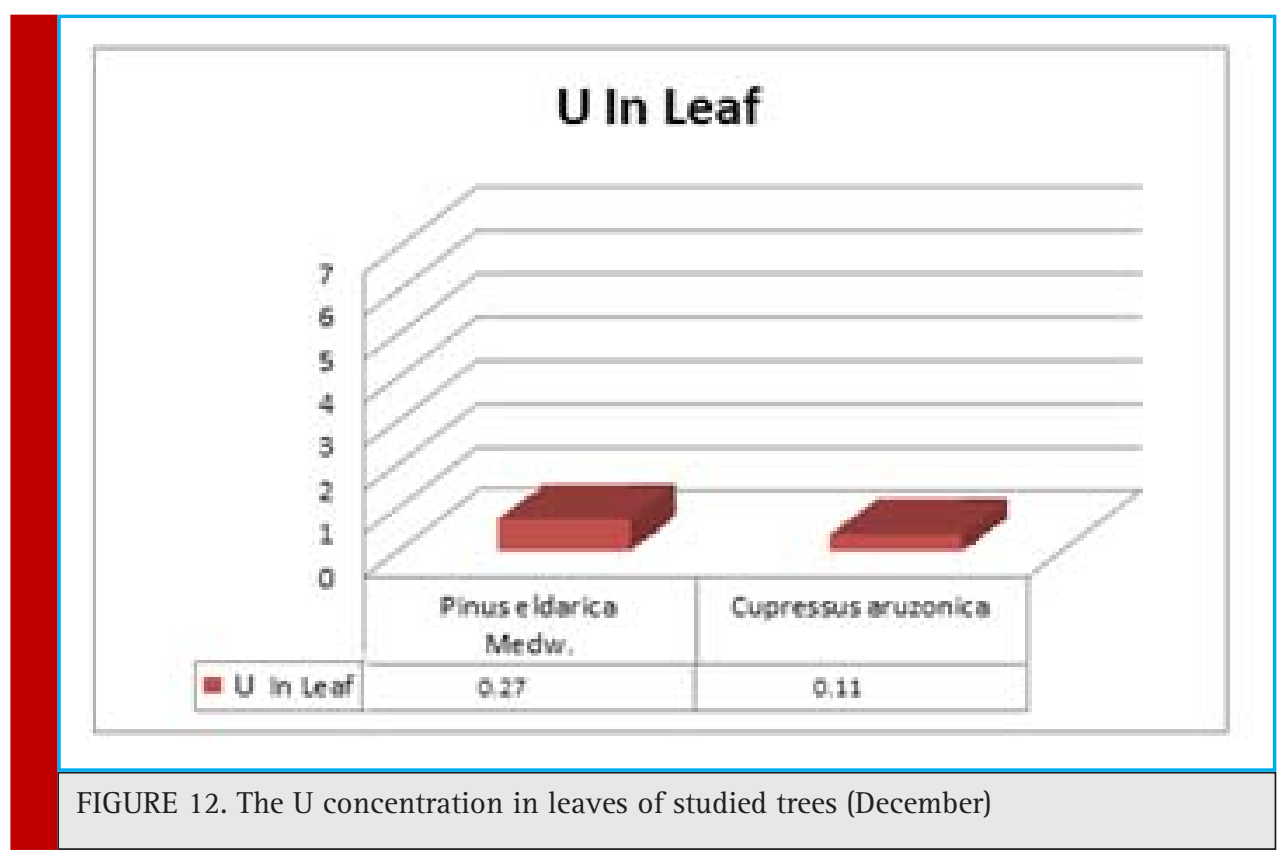

Cheraghi et al (2012) showed that concentration of metals in stem of plants was more than leaves. Moreover, significant correlation was observed between concentration of metals in stem and the sediments. Maddah et al (2013) found that forest pine is suitable specie for $\mathrm{PbPhytoremediation.} \mathrm{In} \mathrm{concentration} \mathrm{of} \mathrm{800ppm,} \mathrm{the}$ contamination of $\mathrm{Pb}$ is in highest level in stem and shoots; although in concentration of 1600ppm, the $\mathrm{Pb}$ contamination is mostly in stem and leaf.

The results obtained from the present study show that the absorption of these metals in tree species studied varies during different times and the process is increased in December and March. As absorption of these elements in plants is a physiologic phenomenon, absorption is decreased in cold months of the year with reduction of temperature and reduction of breathing. Poorfarhadi (1994) and Shahmansuri (1995) studied role of different seasons in absorption level of $\mathrm{Pb}$ in plants and found that the most absorption of $\mathrm{Pb}$ is in summer.Organization of Parks and Green Space of Tehran Municipality (1994) has also reported most $\mathrm{Pb}$ contamination level in plants in late September.

Kardar et al (2015) found that absorption of $\mathrm{Cd}$ in different organs of plant species in polluted station has been more than other stations and the highest $\mathrm{cd}$ absorption level has been attributed to September and the lowest level is observed in June. Shabanian and Cheraghi (2013) showed that contamination of $\mathrm{Zn}, \mathrm{Pb}$ and $\mathrm{Cd}$ in leaves of majority of species in polluted zone has been significantly higher than control zone at the level of 95\%. In polluted zone, the contamination of $\mathrm{Pb}$ and $\mathrm{Cd}$ has been observed in cedar and $\mathrm{Zn}$ in elm and $\mathrm{Mg}$ are also observed mostly inRobinia peseudoacacia.
In this study, in the studied treatments, absorption of metals existed in needle leaf trees has been more than broad leaf trees, so that its increasing process has been observed respectively inPinus Eldarica Medw, Cupressus arizonica Greene and Platanus orientails. It seems that parameters such as being evergreen, more numbers of leaves, high growth speed, the $\mathrm{Cu}$ contamination in soil and ability of transfer from underground to aerial organs can affect increased absorption of metals in needle leaf plants. Lasat (2000) has found that growth speed of species and the coefficient of $\mathrm{Cu}$ transfer from underground to shoots could be the most important factor to increase the element in shoots (leaf and branches). Safdari (2005) has also mentioned that air pollutants can have more effect on needle leaf plants because of being evergreen and because of wider surface of leaf against the airflow.

Moreover, as one of the secondary results of this study, it could be mentioned that through conducting a field study in the zones with probability of emission of radioactive mainly caused by heavy metals such as surrounding areas of nuclear stations and the places for disposal of radioactive materials, through planting tree species with high absorption capability of heavy metals, especially radioactive metals such as U235, U238 and Pu239 found in nuclear wastes abundantly, a reliable method could be found in long-term to measure the amount of emission of radioactive materials from thenuclear disposal plant or reservoirs. Particularly, it could be applied in positions or places, at which Geiger Müller meters or other nuclear sensors can’t be applied for any reason.

The results obtained from this study show that the $\mathrm{Cu}$ absorbed by leaves of studied species is increased 
respectively in Pinus eldarica Medw, Cupressus arizonica Greene and Platanus orientails. Also, the highest absorption level of this metal is observed in leaf of Pinus Eldarica Medw. In terms of the effect of station in absorption of $\mathrm{Cu}$, the species in Mehrabad Airport station have shown highest level of $\mathrm{Cu}$ contamination. The $\mathrm{Zn}$ contamination is also increased in leaves of studied species includingPinus eldarica Medw, Cupressus arizonica Greene and Platanus orientailsand the Pinus eldarica Medwleaves have shown the highest contamination of this metal. The effect of stations on this metal has been also similar to two mentioned metals and has shown highest concentration in species in Mehrabad Station. In this study, it seems that due to the results obtained, uranium concentration absorbed by studied species is increased respectively in Pinus eldarica Medw, Cupressus arizonica Greene and Platanus orientails. The highest uranium contamination is also observed in Pinus eldarica Medwleaves. As it was mentioned, the concentration of uranium in studied species in polluted stations is more than control station and the leaves of Pinus eldarica Medwin Mehrabad Station have shown highest contamination of this metal. Therefore, it could be observed in this study that absorption of $\mathrm{Cu}, \mathrm{Zn}$ and $\mathrm{U}$ in studied trees in polluted zones has been higher than control station and Pinus eldarica Medwcan be applied as an indicator species for contamination of heavy metals such as $\mathrm{Cu}, \mathrm{Zn}$ and Uranium.

\section{REFERENCES}

Afshari Ali, Khademi Hossein and Delavar Mohammad Amir (2015). Evaluation of Heavy Metal Contamination Using Pollution Factor in Soil Land with Different Uses in the Central District of Zanjan Province. Journal of Water and Soil Science, Vol. 25, No. 2.4, 2015, p. 41-52

Baek SO (2017).Determination of heavy metals in the ambient atmosphere. Toxicol Ind Health. 2017 Jan;33(1):79-96.

Cheraghi, M., Dadalahi Sohraab, Saffahieh A., Ghanemi K. and Dorky A. (2012). Investigation of the accumulation of heavy metals in the bed, leaves and roots of the plant (Avicennia marina). In Khuzestan province. Journal of Marine Science and Technology, Volume 11, Number 4, Pages 46-5646

Kardar Saeed, Fatemi Talab Seyed Reza, Saeb Keivan, Khademi Amin (2015). Investigation of the role of Asteroid and Silver Cousin Types in heavy metal cadmium biomass processing (Isfahan case study). Natural Ecosystems of Iran. Article 7, Volume 6, Issue 2, Successive Issue 19, Summer 2013, Page 89-96
Kord Behrooz, Khademi Amin and Abbasi Sarapour (2011) .Production of lead element by some tree species in urban polluted soils (Tehran). Biostatistics: Autumn 2011, Volume 5, Issue 3 (18); p 109-119.

Maddah Seyedeh Mahdokht, Jalilpour Babak, Shirvani Anushirvan, Moraghebi Farhang, Firouzeh Faezeh (2013). Evaluation of Lead Biomonitoring Efficiency in Soil by Pinus sylvestris Forest Pine Saplings. Plant and Ecosystems:Summer2013, No 35, Issue 9; p 11-20.

Marry, R.H.; Tiller, K.G. and Alston, A.M.,)1986. (The effect of contamination of soil with copper, lead and arsenic on the growth and composition of plant. Journal of Plant and Soil, 91: 115-128.

Naderi, Mohammad Reza, Daneshahrki, Abdul Razaq, Naderi, Rezvan (2012). A review of the planting of soils contaminated with heavy metals. Man and the environment.10. No. 4 (23rd year 34), 35-49

Parks \&t Green Space Organization of Tehran, (1994) Information on the area and number of Tehran parks.

Poorfarhadi, K. (1994). Investigation of Tehran's air leads capture by evergreen plants and determination of resistant species. Master's Degree Program in Environmental Economics, Faculty of Natural Resources, University of Tehran., 108E

Safdari, Vahid Reza, Parsapajouh, Davood, Hamsi, Amir Hooman, Dendrochemistry studies in order to investigate the effects of Tehran air pollution on Pinus eldarica. Environmental Science and Technology, No. 26, 2005

Shah Mansouri, M (1995). Ecological survey of lead-contamination in the river, Journal of Water and Sewage, No. 3-11:

Shanbanian, Naghi and Lamaghi, Chanor (2013). Comparison of heavy metal biopsy by wood species used in urban forestry in Sanandaj. Forest and Poplar Researches of Iran,21 (1), 154-165.

Sistani N., Moin al-Dini Mazeher, Khorasani Nematollah, (2017). Pollution of Heavy Metals in Soils Adjacent to Kerman Steel Industries: Evaluation of Metal Benefit and Degree of Contamination. Journal of Health and Environment, Journal of Research. Iranian Society of Environmental Health. Volume 10, Number 1, Spring 2017, p 75-86

Suvarapu LN, Baek SO (2017). Determination of heavy metals in the ambient atmosphere. Toxicol Ind Health. 2017 Jan; 33(1):79-96

Zhou, X., Chen, Q., Liu, C., \& Fang, Y. (2017). Using Moss to Assess Airborne Heavy Metal Pollution in Taizhou, China. International Journal of Environmental Research and Public Health, 14(4), 430. http://doi.org/10.3390/ijerph14040430

Xu Qiutong and Zhang Mingkui (2017). Heavy Metals Accumulated in Vegetable Soils in the Coastal Plain of Eastern Zhejiang Province, China. Ecotoxicol Environ Saf 142, 410-416. 2017 Apr 28. 